\title{
The experiences of patients living with
}

\section{malignant pleural effusions}

Rachel Jones ${ }^{1}$, Henry Steer ${ }^{1}$, Nancy Preston ${ }^{2}$, Paul Perkins ${ }^{1,3}$

1. Gloucestershire Hospitals NHS Foundation Trust, Cheltenham

2. International Observatory on End of Life Care, Lancaster University

3. Sue Ryder Leckhampton Court Hospice, Cheltenham

To the editor

We commend Twose et al for their qualitative study conducted with sixteen patients who had therapeutic thoracocentesis for malignant pleural effusions (MPE) ${ }^{1}$. Respiratory symptoms improved while constitutional symptoms did not; and even though symptomatic benefit was only for a matter of days, patients thought that it was worth any discomfort.

We conducted a similar study with 10 patients with MPE who were identified by the pleural team at a large district general hospital. Patients were interviewed four weeks after a talc pleurodesis or placement of an in-dwelling pleural catheter (IPC). An IPC is a plastic tube which can be placed during a day case procedure and allows intermittent fluid drainage in the community.

A semi-structured electronically recorded interview was conducted by a researcher following a topic guide,transcribed, and underwent thematic analysis. 
We had a male and mesothelioma preponderance with 8 of 10 male and 6 had mesothelioma. Thoracocentesis was the initial pleural instrumentation for all (some therapeutic, some diagnostic) but subsequently 9 of 10 had an IPC and 6 of 10 had attempted talc pleurodesis (some had both). Pre-procedure symptoms were respiratory and constitutional. For some thoracocentesis was uncomfortable. Where our study differs from Twose et al is the additional data with regard to patients undergoing IPC and pleurodesis.

In general IPC placement was well tolerated and patients liked that as a result of the IPC there was no need to return to hospital for further thoracocentesis. Care at home, with the support of District Nurses was greatly appreciated, despiteoccasional frustrations. For some, placement of an IPC led to a gradual reduction of fluid drainage and pleurodesis with tube removal. For some, subsequent tube removal did not change quality of life, for others it felt liberating.

For those undergoing chest drain and pleurodesis, there was some dissatisfaction that this necessitated a hospital stay and the chest drain bottle was inconvenient, but improvements in quality of life were worth the effort. We asked patients to reflect on the journey they had taken and whether they would have chosen the same pleural interventions again (multiple therapeutic thoracocenteses versus pleurodesis or IPC). Patients fell into two categories: those who thought that the decision should be made by the medical team and those who were keen for a particular option such as IPC or intermittent drainage.

\section{Conclusions}


While our findings with regards to removal of pleural fluid are similar to Twose et al's, our data give some interesting insights into the experiences of patients who have undergone IPC or pleurodesis. Both procedures have burdens and benefits and it is important that patients are guided by clinicians so that they can make informed choices..

Table 1: Perceptions of patients after IPC placement or talc pleurodesis

\begin{tabular}{|c|c|}
\hline Perception of patient & Exemplar quote(s) \\
\hline \multicolumn{2}{|l|}{ IPC } \\
\hline Placement was generally well tolerated & $\begin{array}{l}\text { "It wasn't very pleasant, but it was pain- } \\
\text { free, it was just a lot of, sort of, faffing } \\
\text { position-wise, and pushing, and shoving, } \\
\text { and prodding..." (Patient 7) }\end{array}$ \\
\hline No need to return to hospital & $\begin{array}{l}\text { "I wouldn't want to stay in hospital unless I } \\
\text { really had to." (Patient 1) }\end{array}$ \\
\hline Community support & $\begin{array}{l}\text { "...there was a hiccup the first weekend, } \\
\text { the district nurses didn't turn up." (Patient } \\
\text { 6) }\end{array}$ \\
\hline IPC leading to pleurodesis & $\begin{array}{l}\text { Initially, it was every couple of days, but } \\
\text { now, for the last few weeks, or even four } \\
\text { weeks, it's been weekly" (Patient 5) }\end{array}$ \\
\hline \multicolumn{2}{|l|}{ Talc Pleurodesis } \\
\hline Inconvenience & \\
\hline
\end{tabular}




\begin{tabular}{|l|l|}
\hline \multicolumn{1}{|c|}{ "Oh very definitely,(worth not } \\
having to come to hospital) (Patient 4) \\
"I don't recall any particular pain from it, it \\
was just the fact you wanted to go to the \\
loo you've got to somehow drag this bucket \\
around with you." (Patient 4)
\end{tabular}

\section{REFERENCES}

1 Twose C, Ferris R, Wilson A, et al. Therapeutic thoracentesis symptoms and activity: a qualitative study. BMJ Supportive \& Palliative Care 2021 doi:10.1136/ bmjspcare-2020-002584

\section{ACKNOWLEDGEMENTS}

We are grateful to the patients who participated in this study. 


\section{CONTRIBUTORS}

PP conceived the study. RJ, HS and NP made substantial contribution to its design. RJ collected the data. All authors contributed to the analysis and interpretation of the data and critically revised drafts of the paper. They also read and approved the final version of the manuscript. PP is the guarantor.

\section{FUNDING}

Funding for this study was received from the Gloucestershire Hospitals Chest Fund and the Gloucestershire Hospitals NHS Foundation Trust Research and Innovation Forum Fund.

\section{COMPETING INTERESTS}

All authors have completed the Unified Competing Interests form at http://www.icmje.org/coi_disclosure.pdf (available on request from the corresponding author). There are no competing interests.

APPROVALS/ETHICS

The study was approved by Gloucestershire Research Support Service, the Sue Ryder Research Governance Group, the National Research Ethics Service Committee West Midlands (REC Reference 16/WM/0222).

\section{PROVENANCE AND PEER REVIEW}

Not commissioned; externally peer reviewed.

\section{DATA SHARING STATEMENT}

Unpublished data are held by Sue Ryder Leckhampton Court Hospice. 